\section{Raquel Chang-Rodríguez:}

Distinguished Professor de literatura y cultura hispanoamericanas en el Graduate Center y el City College de la City University of New York (CUNY). Entre sus más recientes publicaciones se encuentran la edición anotada y modernizada de la obra de Clarinda y Amarilis, las poetas anónimas del Perú (PUCP, 2009); y «Aquí, ninfas del sur, venid ligeras». Voces poéticas virreinales (Iberoamericana/Vervuert, 2008). En 2006 editó una colección de ensayos que apareció simultáneamente en español, Franqueando fronteras: Garcilaso de la Vega y «La Florida del Inca» (Lima, PUCP), y en inglés, Beyond Books and Borders: Garcilaso de la Vega and "La Florida del Inca" (Lewisburg, Bucknell UP). En 1992 fundó la revista interdisciplinaria Colonial Latin American Review. Fue becaria, entre otras instituciones, de la National Endowment for the Humanities (NEH); es Profesora Honoraria de la Universidad Nacional Mayor de San Marcos y Miembro Correspondiente de la Academia Peruana de la Lengua.

1

Agradezco a Juan Ossio y José Antonio Mazzotti la lectura de una primera versión de este ensayo y sus sugerencias.

2

La parada en esta capital no fue obligatoria hasta 1564, cuando se reorganizó en Sevilla el sistema de flotas. Si bien en Comentarios Reales hay varias menciones a las Islas de Barlovento, Santo Domingo y Cuba que denotan un conocimiento de la geografía y de los asuntos caribeños - recordemos e relato intercalado sobre Pedro Serrano-, no se registra un incidente particular donde el narrador verifique su presencia en La Habana.

3

En La Florida del Inca (1605) indica que la primera tierra que vio al entrar en Europa fue la de Portugal. Llama Lisbona a su capital, comenta el buen trato y los favores allí recibidos - lo salvaron de la muerte- - La Florida del Inca, Emma Susana Speratti Piñero (ed.), México, FCE, 1956, Dedicatoria, 3. Sin embargo, en $C R$ no trata el tema e ignoramos las circunstancias por las cuales su vida peligró en la urbe lusitana. Todas las citas de La Florida del Inca provienen de la citada edición de Speratti Piñero; en el texto indicamos libro, parte, capítulo y número de página.

La ruta del Inca Garcilaso RAQUEL CHANG-RODRÍGUEZ

\title{
LA RUTA DEL INCA GARCILASO
}

RAQUEL CHANG-RODRÍGUEZ

The City College-Graduate Center, City University of New York (CUNY)

Como todo viajero en una travesía transatlántica, el Inca Garcilaso visitó varias ciudades americanas y europeas antes de llegar a su destino. Conocemos el rumbo del periplo que alejó para siempre al joven Gómez Suárez de Figueroa de su suelo nativo. En pleno verano austral, el 20 de enero de 1560 salió del Cuzco para pasar a Lima o Ciudad de los Reyes, y de allí al puerto del Callao desde donde zarpó, el 4 de marzo de 1560, hacia España. En Paita hizo una primera escala, y después una segunda en el cabo de Passau, situado en el país moderno de Ecuador. Por la calma de los vientos, la nave hizo otra parada en la Isla de la Gorgona. El viajero se detuvo en Panamá, cruzó el istmo, y en Nombre de Dios esperó la llegada de la flota que lo llevó a Cartagena, y probablemente a La Habana ${ }^{2}$, para zarpar rumbo al Viejo Mundo. El joven cuzqueño entró a este por las islas Azores, y al continente por Lisboa ${ }^{3}$ desde donde siguió a Sevilla, entonces conocida como "puerta de las Indias» ${ }^{4}$.

Fino observador de su entorno, el cronista describirá en Comentarios reales (1609; 1617) la geografía costera, advertirá sobre la navegación o dará detalles de las gentes y villas donde su barco hizo escala. Lo visto en esa travesía con frecuencia informa sus reflexiones sobre la conquista, la naturaleza americana y su propia persona. En este ensayo me propongo explorar instancias de la primera y segunda partes de esta obra maestra con el propósito de mostrar cómo el periplo transatlántico, recordado desde la distancia de

4

Aurelio Miró Quesada, El Inca Esta línea de indagación la Garcilaso, Lima, PUCP, pp. propició José Antonio Mazzo99-101. propició José Antonio Mazzo-
tti en su libro Coros mestizos del Inca Garcilaso: resonan- los años, cuando el autor escribía su crónica en Montilla y Córdoba, se integra a una compleja meditación donde el mestizo cuzqueño entreteje, valiéndose de anécdotas, datos inusitados y curiosas observaciones, ideas que marcan tanto su concepto de la historia como percepción de América y sus habitantes. Al deshilvanar los hilos de tan compleja trama, e intentar entender por qué se seleccionan ciertas ocurrencias - más allá del anunciado propósito de entretener, de servir de ejemplo o de variar el ritmo del relato ya de la historia de los soberanos del Incario, ya de los sucesos de la conquista del Perú-, quiero dirigirme a la estructura profunda ${ }^{5}$ de la obra, término asociado con el estructuralismo, particularmente con las ideas de Chomsky, Greimas y Todorov, pero cuyos parámetros los esbozó antes con mayor claridad Kenneth Burke. En su Grammar of Motives el lingüista y crítico literario norteamericano propuso el estudio de cinco instancias - el acto (qué se hizo); la escena (cúando o dónde se realizó); el agente (quién lo hizo); la agencia (cómo se hizo); y el propósito (por qué se hizo) - cuya interrelación determina el acto narrativo; el énfasis en una o varias de ellas nos permite una interpretación específica del texto ${ }^{6}$. Si a ello agregamos el estudio de la metáfora, la metonimia, la sinécdoque y la ironía - según Burke, las cuatro figuras maestras del lenguaje-, podremos llegar a «la verdad», aquí entrecomillada porque los actos y tropos erigen esa realidad. En otras palabras, el análisis propuesto por Burke nos lleva a entender

$\begin{array}{ll}\text { cias andinas, Lima, F.C.E., } & \begin{array}{l}\text { varios capítulos de Kennteth } \\ \text { Burke, Grammar of Motives, } \\ \text { Berkeley, University of Califor- } \\ 6\end{array} \\ \text { nia Press, } 1969 .\end{array}$


el cómo y el porqué del acto narrativo, y a entrever esa estructura trascendente, más allá de los sucesos contados, o del accionar de los personajes. De las instancias propuestas me interesa particularmente la escena - en este caso, los lugares evocados donde hallamos al narrador afirmando su presencia - y entender la incidencia de estas observaciones en el ámbito mayor de Comentarios reales. Propongo entonces analizar ambas instancias siguiendo el rumbo de ese viaje para de este modo acceder al recorrido ideológico que anima al narrador, marca su discurso y ofrece la ruta simbólica de un inusitado trayecto intelectual. Me concentraré en lugares con seguridad visitados por el Inca, y donde la voz del autor se explaya o se minimiza denotando su carácter de testigo y matizando lo contado: el cabo de Passau, Cartagena de Indias, Lima, Panamá y Sevilla.

\section{El cabo de Passau y la zona tórrida}

En este remoto lugar en la costa de la actual provincia de Manabí, en el Ecuador, se detuvo la nave en la cual viajaba Gómez Suárez de Figueroa para abastecerse de agua y leña. En el entramado de la crónica, el sitio marca el límite norte del imperio incaico, y está ubicado justo donde pasa perpendicularmente la línea equinoccional. El cabo de Passau, en efecto, aparece mencionado en el crucial primer libro del primer capítulo titulado «Si hay muchos mundos. Trata de las cinco zonas» (CR: 1 , libro 1, cap. 1, pp. 11-13) donde el Inca afirma la unidad del orbe y sus habitantes así como la habitabilidad de la zona tórrida. ${ }^{7}$ Matiza el último aserto acudiendo a su experiencia personal, en particular, su nacimiento en el Cuzco, en la zona tórrida; su paso por las dos zonas templadas - la del sur, en la zona de los Charcas, «de la otra parte del trópico de Capricornio", y la del norte, en Montilla y Córdoba donde escribe su crónica-. Antes de llegar a esta última zona templada, el narrador, según aclara, transitó «por la tórrida» y la atravesó toda y estuvo «tres días naturales debaxo de la línea equinoccial, donde dizen que passa perpendicularmente, que es en el cabo de Passau». Tomando lo anterior en cuenta, concluye «que es habitable la tórrida como también las templadas» (CR: 1, libro 1 , cap. 1, p. 12).

Para entender la centralidad de estos asertos, conviene recordar que durante el me- dioevo se creía que la tierra estaba dividida en dos grandes masas respondiendo así al perfectamente simétrico plan divino. La masa al sur del globo se denominaba «Antípodas» y cualquiera que la visitara debía andar al revés, con los pies en opuesta posición a quienes vivían en el norte. Si bien se debatió si esta región era habitable o no, la mayoría creía que nadie podía vivir allá. Esto se debió a la teoría prevaleciente sobre las zonas climáticas, de raigambre aristotélica, ${ }^{8}$ anunciada por el título de este capítulo: las frías en los polos; otra calentísima en el ecuador; y otras dos templadas, entre la fría y la caliente, al norte y al sur; la temperatura de cada una estaba regulada por la cercanía o lejanía al sol. Si bien esta conclusión no es incorrecta, sí fue un error proponer la imposibilidad de pasar de una zona a la otra porque la proximidad al sol podía matar a quienes se atrevieran a hacerlo. Claro que cuando el Inca escribía sus Comentarios reales, anteriores viajes de navegación -en particular de pilotos portugueses - ya habían probado la inexactitud de tales ideas; no obstante, el mito estaba muy arraigado; al mismo tiempo, a partir de los viajes colombinos, habían surgido otros en torno, por ejemplo, a la falta de capacidad de los habitantes de la zona tórrida9. Esto se evidencia en la actitud del narrador de Comentarios reales quien parece escribir apremiado por desmentir estas equivocaciones, y así nota: 1) su nacimiento en la zona tórrida, 2) visita a la zona templada del sur, 3) estancia temporal en el cabo de Passau en la tórrida, y 4) eventual relocalización a Europa, en la templada del norte. Cuando añade que escribe desde esa zona, subraya, acudiendo nuevamente a su experiencia, la posibilidad del tránsito de una a otra, así como resalta que él ha realizado el trayecto, sin quemarse y conservando las facultades mentales que le permiten acceder a la escritura alfabética en la redacción de su crónica, el más elevado de los ejercicios intelectuales. Las observaciones sobre la parada en el remoto cabo de Passau le otorgan al narrador la oportunidad de afirmar contundentemente la habitabilidad de la zona tórrida, la plena capacidad de quienes allí viven y la posibilidad de pasar de una zona a otra sin mella física ni mental. De este modo el mestizo peruano contradice al admirado Aristóteles - como antes había hecho el jesuita José de Acosta, especialmente en el Libro 2 de su Historia natural y moral de las Indias-, y

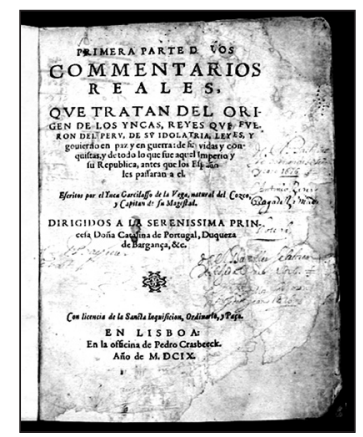

1. Portada, primera parte de Comentarios reales, Lisboa, 1609. Cortesía de la Hispanic Society of America, Nueva York.

7

Todas las citas de Comentarios reales $(C R)$ e Historia general del Perú (HG) provienen de la edición de Ángel Rosenblat: Comentarios reales, Buenos Aires, 2 vols., Emecé, 1943; Historia general del Perú, 3 vols., Buenos Aires, Emecé, 1944. Indico entre paréntesis el tomo, el libro, el capítulo y la página.

8

Aristóteles dividió el mundo conocido en tres zonas climáticas de acuerdo con su lejanía o cercanía al sol: ártica, tórrida y templada. Según sus ideas, únicamente la templada era habitable. Después se agregaron otras dos zonas: la templada, al sur de la línea ecuatorial, y la fría en el polo Antártico.

9

Sobre el tema véanse Antonello Gerbi, La naturaleza de las Indias Nuevas. De Cristóbal Colón a Gonzalo Fernández de Oviedo, Antonio Alatorre (trad.), México, F. C. E., 1978, y Walter Mignolo, The Darker Side of the Renaissance: Literacy, Territoriality and Colonization, Ann Arbor, Michigan University Press, 1995.

La ruta del Inca Garcilaso RAQUEL CHANG-RODRÍGUEZ 


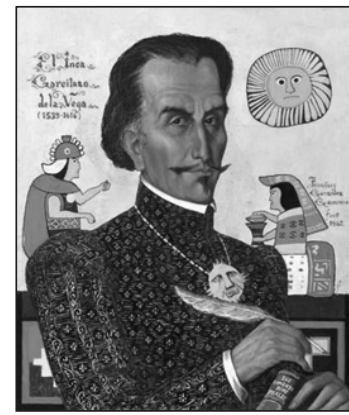

Inca Garcilaso de la Vega.

10

En su edición de Comentarios reales, Lima, FCE, 1991, t. 2 p. 810, Carlos Araníbar señala que la conclusión es una paráfrasis de Cieza de León.

11

Miró Quesada, op. cit., p. 99

12

Para una revisión de las ideas sobre la esclavitud, véase Peter Garnsey, Ideas of Slavery from Aristotle to Augustine, Cambridge, Cambridge University Press, 1996.

La ruta del Inca Garcilaso RAQUEL CHANG-RODRÍGUEZ a la vez se asocia al pensamiento más moderno de la época, acudiendo a la experiencia y no al saber recibido.

El cabo de Passau figura al menos en otros dos libros de Comentarios reales donde el narrador lo relaciona con la historia de los Incas. En el capítulo décimo del primer libro dedicado a la variedad de dioses adorados por los nativos de los Andes, el cabo también marca el límite norte del imperio. El narrador, además, se detiene en notar la falta de inclinación de sus habitantes a venerar ni cosa ni persona «baxa ni alta» porque «vivían y viven hoy como bestias y peores porque no llegó a ellos la doctrina y enseñança de los Reyes Incas» (CR: 1, libro 1, cap. 10, pp. 31-32). Passau reaparece en el libro noveno cuando el narrador describe los dioses, costumbres y reducción de los Manta «y la de otras [naciones] muy bárbaras» entre las cuales ubica a los habitantes del cabo de Passau. Repite aquí su localización debajo de la línea equinoccial y los describe como «barbaríssimos sobre cuantas nasciones sujeraton los Incas». Esa extrema bestialidad se confirma por medio de los tópicos tradicionales asociados con la humanidad americana: andan desnudos, con los labios horadados, la cara pintada, los cabellos mugrientos; no tienen casas, ni agricultura, ni mujeres conocidas; son ignorantes de sus hijos y abiertamente sodomitas. El narrador corrobora su descripción acudiendo de nuevo a su carácter de testigo presencial y afirma: «Yo los vi por mis ojos cuando vine a España ... que paró allí nuestro navío... verdaderamente eran selvajes, de los más selváticos que se pueden imaginar». Ratifica su juicio invocando la decisión de Huaina Cápac Inca, quien resuelve no conquistarlos pues por su bestialidad no merecían tenerlo por señor y dejó «a los naturales de Passau tan torpes y brutos como antes se estavan» (CR: 2, libro 9, cap. 8, pp. 234-235) ${ }^{10}$. Comentarios tan negativos llevaron a Miró Quesada a conjeturar sobre un posible contratiempo del cronista cuando pasó por esas tierras, o a atribuir las observaciones peyorativas al calor tropical o a la ansiedad del viajero por llegar a su destino $^{11}$.

Por mi parte, indagando sobre el motivo para incluir estas observaciones y así horadar la estructura profunda del discurso, quisiera recordar la praeparatio evangelica, doctrina atribuida a Eusebio de Cesarea (c. 275-339) donde este obispo explica la importancia del sustrato helénico en la recepción del cristianismo. Como sabemos, Garcilaso en todo momento destaca la labor civilizadora de los soberanos del Tahuantinsuyo con respecto a la humanidad andina en «behetría»-como antes griegos y romanos, estos allanarían el camino para la recepción del cristianismo-; igualmente, se detiene en las diversas etapas por las cuales ha pasado este conjunto de pueblos hasta que, gracias al buen gobierno incaico, están listos a recibir el Evangelio. La superioridad de los Incas con respecto a los habitantes del cabo de Passau y otros grupos la reitera el citado comentario de Huaina Cápac. Entonces, al enfrentarse con la barbarie de los moradores del cabo y traerla a colación como ejemplo máximo de esta, el narrador enaltece a sus ancestros cuando insiste en lo arduo de la labor colonizadora incaica, efectuada predominantemente por medio de la mediación y la retórica del convencimiento. ¿Se insinúa entonces que sujetos tan bestiales deben ser súbditos de señores igualmente salvajes, cuyas conquistas se efectúan a sangre y fuego, y no de los «pacíficos» y «diplomáticos» Incas? ¿ O acaso el narrador señala el desafío de España: por un lado, terminar la inconclusa labor de los soberanos del Tahuantinsuyo evangelizando a los grupos «preparados» para ello, y, por otro, aculturar y cristianizar a los conglomerados humanos excluidos del Incario y ahora bajo la tutela de la Corona y del Papa? ¿O quizá por medio de esta reiteración del barbarismo Garcilaso se adhiere a la propuesta aristotélica: los seres deficientes, tales como los habitantes de Passau, deben subordinarse a sus superiores intelectual y moralmente? ${ }^{12}$. Se insinúa una respuesta cuando el tema de la barbarie aflora de nuevo en la parada en Cartagena de Indias.

\section{Cartagena de Indias: caminaban «como grullas»}

Cuando Gómez Suárez de Figueroa pasó a Cartagena, fundada en 1533 por el conquistador Pedro de Heredia en territorio de los indígenas de la etnia calamarí, todavía la villa no tenía sus famosas murallas; piratas franceses la habían saqueado en 1544 y 1559. A partir de 1560, el año en que el joven cuzqueño la visitó, comenzaron a erigirse fortificaciones para protegerla de los enemigos de España; los esfuerzos se multiplicaron más tarde, después del exitoso asedio de Francis Drake en 
1586. En 1564, al regularse el comercio con las Indias por medio de las flotas, Cartagena del Poniente, como se la llamó inicialmente para distinguirla de Cartagena del Levante en España, era un importante fondeadero, parada imprescindible de los barcos ocupados en la «carrera de Indias», y sede del comercio dirigido tanto al norte como al sur del continente y, en el torna viaje, a Europa. En el siglo XVII se estableció allí la Inquisición (1610); también en esa centuria Cartagena recibió un gran número de esclavos africanos distribuidos en el continente y en las islas del Caribe. Si bien cuando Gómez Suárez la visitó, la villa distaba mucho de ser el puerto principal descrito por el poeta Hernando Domínguez Camargo (1606-1659) como «Esta, de nuestra América pupila...», para entonces Cartagena del Poniente era un reconocido centro de intercambio mercantil.

En Comentarios reales hallamos un destello de ese alto en la ciudad caribeña. En el apartado dedicado a «Cómo se vestían en aquella antigüedad», el narrador nuevamente incide en la importancia del atuendo como frontera entre la civilización y la barbarie: los indios de la «primera edad» vestían «como animales» porque su ropa era su piel; algunos traían un hilo grueso «ceñido al cuerpo». El narrador previene y suplica a los «oídos honestos» abstenerse de «escuchar» estas descripciones que su prurito de buen historiador le exige contar completa y detalladamente. En este contexto reitera su carácter de testigo presencial y explica: «El año de mil quinientos y sesenta, viniendo a España, topé en una calle, de las de Cartagena, cinco indios sin ropa alguna, y no ivan todos juntos, sino uno en pos de otro como grullas, con haver tantos años que tratavan con españoles» (CR: 1 , libro 1 , cap. 13, p. 36).

Si bien andar «como grullas» fue, como señala Araníbar, un giro lingüístico de entonces $^{13}$, equivalente al actual «andar uno detrás de otro", dada la importancia de la emblemática en la época y teniendo en cuenta que los jesuitas, con cuya orden el cronista tuvo vínculos estrechos, se aprovecharon de esta como método de instrucción, vale repasar las características asociadas con las grullas ${ }^{14}$. Estas aves se consideraban notables, en el ámbito de la emblemática, por un comportamiento solidario: mientras unas descansan, otra vela para prevenir a la bandada de cualquier peligro; para no dormirse, la grulla vigilante sostiene

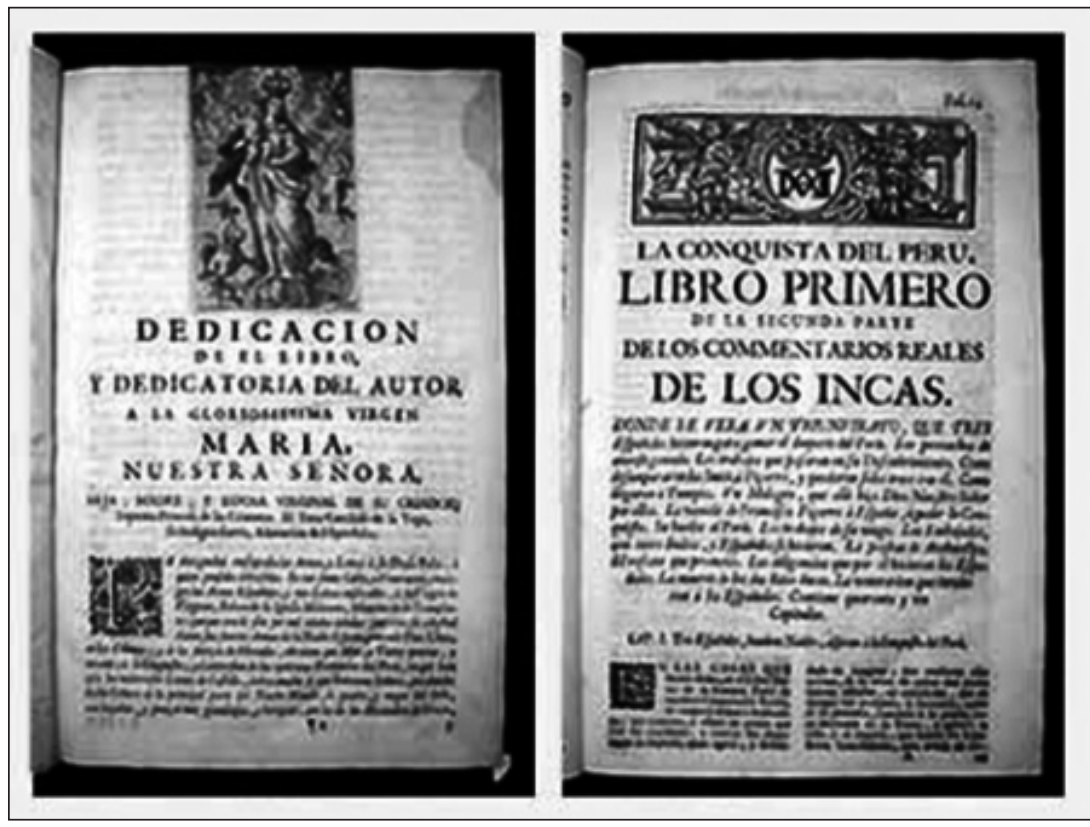

2. Detalle interior de la segunda parte de Comentarios reales, también conocida como Historia general del Perú, Córdoba, 1617. Cortesía de la Hispanic Society of America, Nueva York.

una piedra en la pata. Otros las asociaron con el silencio, virtud imprescindible del buen príncipe, porque vuelan con una piedra en la boca; también las ligaron a la prudencia por aletear con una piedra en la pata para evitar que el viento las apartara del camino ${ }^{15}$. Por todo ello, como nos recuerda Martínez Pereira, las grullas figuraron prominentemente en los libros de emblemas españoles representando diferentes virtudes y modelos de comportamiento aplicados, en los siglos XVI y XVII, a la política, la sociedad y la educación del príncipe $^{16}$. Por otro lado, tratadistas de la talla del sevillano Pedro Mexía (1498-1551), cuya popular Silva de varia lección (1540) se encontraba entre los libros de la biblioteca del Inca ${ }^{17}$, meditaron sobre cómo el comportamiento del mundo animal podía servir de modelo a los humanos. El capítulo 28 del citado compendio se titula: «Cómo de los aves y animales pueden tomar ejemplo y reglas para bien y virtuosamente vivir los hombres»; en este Mexía detalla la conducta de la hormiga, la abeja, el camello, la paloma, la tórtola, el pavo real, el gallo, la cigüeña, el elefante, el perro, el papagayo, el ruiseñor, la golondrina, la araña, el conejo, la vulpeja, la serpiente, la oveja, el león, y concluye: «con los otros animales brutos van enseñando a ser hombres racionales e aun spirituales» ${ }^{18}$.

Tomando lo anterior en cuenta así como la familiaridad del lector de la época con
13 Araníbar, op. cit., t. 2, p. 749

14

Como es bien sabido, los jesuitas los utilizaron para la enseñanza en la ratio studiorum, y los propagaron dentro y fuera de sus colegios.

15

Ana Martínez Pereira, «El símbolo de la grulla en la emblemática española», Revista da Faculdade de Letras (Oporto), 20 (2003), pp. 335-342.

16

Op. cit., p. 234.

17

Según José Durand, "La biblioteca del Inca», Nueva Revista de Filología Hispánica, 2 (1948), p. 251, Silba de baria lezión, es el número 79 en la lista del inventario de los libros de la biblioteca de Garcilaso.

18

Pedro Mexía, Silva de varia lección, Isaías Lerner (ed.), Madrid Castalia, 2003, p. 685.

La ruta del Inca Garcilaso RAQUEL CHANG-RODRÍGUEZ 
19

Más adelante señala que los indígenas, tanto mujeres como hombres, que viven en proximidad a los españoles se visten porque estos los importunan y no por decoro (CR: 1, libro 1, cap. 13, p. 37).

20

"Que por esperiencia muy clara se ha notado cuánto más promptos y ágiles estavan para recebir el Evangelio los indios que los Reyes Incas sujetaron, governaron y enseñaron, que no las demás naciones comarcanas, donde aún no havía llegado la enseñanza de los Incas, muchas de las cuales se están hoy tan bárbaras y brutas como antes se estavan, con haver setenta y un años que los españoles entraron en el Perú (CR: 1, libro 1, cap. 15, p. 39).

21

Para 1524 Darién estaba totalmente abandonada.

22

A consecuencia del devastador ataque de Henry Morgan (1671), la villa se relocalizó a unos 13 kilómetros al oeste; Antonio Fernández de Córdoba efectuó la nueva fundación en 1673.

La ruta del Inca Garcilaso RAQUEL CHANG-RODRÍGUEZ las analogías y comparaciones propuestas por los libros de emblema y la literatura de ingenio, no sería desacertado proponer que el andar indígena asociado con estas aves conlleva igualmente una relación con sus virtudes. Si en las aves un tipo de conducta promueve la solidaridad y la protección del grupo, en el caso de los nativos, su asociación con las grullas bien podía insinuar su posibilidad de alejarse de la primera edad bárbara; y, con buena guía - como la de los Incas -, su eventual ingreso a la etapa propicia para recibir el Evangelio. Propongo que el narrador se detiene en este incidente tan breve como destellante, con el propósito de cuestionar el impacto del método colonizador español: este no ha hecho mella en ese estado de barbarie, implícito en la desnudez indígena, y, mucho menos, en la comprensión del porqué del vestuario en el contexto social de una ética cristiana ${ }^{19}$. Dicho en otras palabras, la carencia de cultura relacionada por los europeos con la apariencia y la falta de ropa no debe ligarse a una insuficiencia de las cualidades necesarias para vivir en la polis; al contrario, el narrador tácitamente pone el acento en lo positivo del binomio grullas/nativos, y así implica el esfuerzo de los soberanos del Incario, quienes condujeron con éxito a diversas etnias en el tránsito de una edad a la otra ${ }^{20}$. Que tanto en el remoto cabo de Passau como en la comercializada Cartagena, después de veintisiete años de fundada la ciudad y a setentaiocho años de la llegada de Colón a las islas del Caribe, el viajero encuentre a indios viviendo como en la primera y «oscura» edad, expone las debilidades tanto de la empresa colonizadora como de la labor evangelizadora de España. Entonces, la referencia a las grullas, más allá de la simple comparación, adquiere un significado diverso: propicia la asociación del comportamiento ejemplar de estas aves con el de indígenas aparentemente bárbaros pero cuyas cualidades inherentes - su humanidad - los capacitan para la vida comunitaria y la recepción del Evangelio. La desnudez puede cubrirse y la vida en la polis puede llevarse a cabo siempre y cuando haya un liderazgo efectivo. Las referencias a otros animales, en particular insectos y roedores, se prodigan igualmente en torno a Lima y Panamá pero en circunstancias disímiles.

\section{Los mosquitos de Lima y las ratas de $\mathrm{Pa}$ - namá}

En el caso de Lima, el narrador ofrece datos sobre su fundación, describe su trazado y arquitectura, contrasta los techos de adobe y paja con los de teja del Cuzco, comenta sobre su clima caluroso comparándolo con el de Andalucía y se detiene a explicar las dos clases de mosquitos - unos atacan de día y otros de noche-, abundantes en la costa y en esa ciudad. Sus observaciones sobre los mosquitos diurnos son minuciosas: amarillos «como una gualda», $\tan$ «golosos de sangre» que la chupan hasta reventar. Para comprobar esto último el joven viajero se deja picar y así verificó que, una vez hartos de sangre, estos insectos «no podían levantarse y se dexavan rodar para irse» (HG: 1, libro 2, cap. 17, pp. 152-153). No contento con lo escuchado, el incrédulo Gómez Suárez de Figueroa se sometió a un mini experimento que le permitió dar cuenta de la fiereza de los mosquitos diurnos y así autorizar lo contado. De nuevo resalta su espíritu moderno al fundamentar su relato con el resultado de observaciones hechas in situ y comprobar la fiereza y glotonería de estos insectos en su propia persona. Una vez más acude a su carácter de testigo presencial $-y$ en esta ocasión hasta de víctima- para ofrecer prueba irrefutable de los hechos.

En cuanto a la parada del Inca Garcilaso en Panamá, conviene recordar que desde Santa María la Antigua de Darién (1510)21 , la primera población española fundada en el istmo entonces conocido como Tierra Firme, salió Vasco Núñez de Balboa en la expedición que dio a conocer el océano Pacífico y posibilitó la exploración del sur del continente. En 1519 el conquistador Pedrarias Dávila, quien antes había mandado decapitar a Núñez de Balboa, relocalizó la villa y la rebautizó Nuestra Señora de la Asunción de Panamá; después esta se convirtió en parada obligatoria para quienes iban o venían del Perú, y en efecto ${ }^{22}$, fue aquí donde Garcilaso hizo escala en su viaje a la Península. La referencia a Panamá y lo visto allí se ofrece en el contexto de un debate donde disputa si las ratas y los ratones son oriundos de América. En cuanto a los segundos, aporta su nombre en quechua (ucucha), admite que los hubo y corrige al cronista Francisco López de Gómara (1511-1566), quien en su Historia general de las Indias (1552) había negado su presencia en los Andes. En cuanto a las pri- 
meras, acota lo siguiente: «Resta dezir de las ratas, que también passaron con los españoles, que antes dellos no las havía» (CR: 2, libro 9, cap. 22, p. 261). Estos roedores, según explica el narrador, se han extendido infinitamente por los pueblos de la costa y son tan grandes que los gatos no se atreven ni a mirarlos ni a atacarlos. Para controlar la plaga, en Panamá, en Nombre de Dios y otras villas costeras, en días escogidos y anunciados por pregones, los vecinos echan «rejalgar» (arsénico) en los alimentos más gustados por las ratas. En Panamá, sitio de cruce, el viajero observó el resultado de este método de saneamiento: «devía de haver poco que se havía hecho el castigo [la desinfección]... saliendo a pasearme una tarde por la ribera del mar, hallé a la lengua del agua tantas [ratas] muertas, que en más de cien passos de largo y tres o cuatro de ancho no havía dónde poner los pies...» (CR: 2, libro 9, cap. 22, p. 262). El narrador intercala a continuación un divertido relato donde un enfermo se defiende de las ratas armado de un asador y mata 380; la lucha trae al menos dos consecuencias positivas: elimina los roedores y el enfermo sana. El capítulo concluye recordando las plagas de ratas y los «daños increíbles» que causan en las sementeras, las heredades, los árboles frutales, "que desde el suelo hasta los pimpollos les roían las cortezas; de manera que los árboles se secaron, que fue menester plantarlos de nuevo, y las gentes temieron desamparar sus pueblos ... y sucediera el hecho según la plaga se encendía, sino que Dios, por su misericordia, la apagava cuando más encendida andava la peste» ( $C R$ : 2, libro 9, cap. 22, p. 263) 23 .

Sostengo que la inclusión de las observaciones sobre las ratas no es casual. Veamos por qué. En el imaginario occidental están asociadas con la enfermedad y la muerte ${ }^{24}$, con la avaricia y el parasitismo ${ }^{25}$. Al ligar su abundancia a los vocablos «plaga» y «peste», el narrador trae a la narración la memoria de las pestes europeas, en particular la de fines del siglo XIV, propagada por los barcos que venían del Asia cuyas ratas traían la pulga y, al picar al humano, lo contagiaban con el patógeno de la enfermedad. Igualmente, la referencia trae a colación la destrucción - el Apocalipsis-, el temor al castigo divino y el autoexamen propuesto por estas circunstancias extremas. Como las pandemias y epidemias (viruela, sarampión, tifus, malaria, fiebre amarilla, gripe) no fueron extrañas en América, y su devasta- dor efecto muy temido, particularmente entre la población indígena carente de inmunidad a las enfermedades importadas, sin duda la lectura del pasaje por lectores muy variados logró evocar sucesos trágicos, tanto lejanos en el espacio y el tiempo (en el Viejo Mundo) como próximos geográfica y temporalmente (en el Nuevo Mundo) ${ }^{26}$.

En particular, durante el siglo XVI, según confirman las investigaciones de Noble D. Cook, las siguientes epidemias asolaron la zona andina: 1524-28, viruela; 1531-33, sarampión; 1546, tifus; 1557-62, sarampión, viruela, gripe; 1597 , sarampión ${ }^{27}$. En el caso del Tahuantinsuyo, las consecuencias de la primera pandemia de viruela fueron nefastas. De acuerdo a los testimonios recavados por tempranos cronistas españoles (Pedro Pizarro, Miguel Cabello de Balboa, Pedro Sarmiento de Gamboa), la enfermedad asoló tanto al Cuzco como a la recién conquistada Quito y territorios aledaños; en la capital del Incario la mortandad fue mucha; en la zona de Tumipampa segó la vida del Inca Huayna Cápac (c.1524) y de Ninan Cuyoche, el presunto heredero ${ }^{28}$. Así, en el mundo andino el efecto de esta plaga fue múltiple y trágico: por un lado, sembró la desolación y la muerte en la zona de la serranía; por otro, acabó con el soberano del Incario y el príncipe heredero, víctimas de la plaga. La desaparición de ambos fue causa directa de la lucha fratricida entre Huáscar y Atahualpa; y a la vez propició la entrada española en territorio inca y la sujeción del imperio. Lectores y escuchas de cualquier procedencia étnica o localización, no tuvieron ninguna dificultad en asociar lo narrado sobre la plaga de ratas con el desastre, la destrucción y los múltiples males, consecuencia de pandemias y epidemias.

Si comparamos este capítulo con otro del libro nueve, «De la hortaliza y yervas y de la grandeza dellas» (CR: 2, libro 9, cap. 29, pp. 273-277), donde el Inca destaca el crecimiento desmesurado de las plantas importadas de España en el suelo andino, el significado de la observación sobre las ratas en el espacio textual se hace aparente. Si en el antes mencionado capítulo veintinueve (sobre las plantas importadas) el narrador hace hincapié en las bondades de los nuevos cultivos, en el veintidós (sobre las ratas de Panamá) describe el efecto dañino que los innumerables roedores causan en las labranzas. Ambos (plantas y ratas) están ligados por su origen extranjero
23

En Mexía encontramos: "Gran multitud de ratones, destruyendo totalmente las raíces de los árboles e yerbas... lo hicieron despoblar, e de hambre los desampararon los que allí [en algunos lugares de Italia] moraban» (Mexía, op. cit, p. 522). Como observa Lerner, al colocar el descontrol de los animales en el contexto del pecado original, Mexía cristianiza un antiguo motivo (Lerner, op. cit, p. 522, n 14). Me pregunto si en el caso de los $C R$ podemos ubicar esta ocurrencia en el contexto del castigo divino a quienes han traído las ratas y las plagas.

24

J. E. Cirlot, A Dictionary of Symbols, 2a. ed., Nueva York, Philosophical Library, 1981, p. 272.

25

Jean Chevalier y Alain Gheerbrandt, Diccionario de los símbolos, Manuel Silvar y Arturo Rodríguez (trad.), Barcelona, Herder, 1993, pp. 869-870

26

Noble D. Cook, en Born to Die: Disease and New World Conquest, 1492-1650, Cambridge, Cambridge University Press, 1998, sostiene con pruebas irrefutables que las pandemias $y$ epidemias contribuyeron tanto como la espada al exterminio y eventual sujeción de los amerindios.

27 lbid., p. 132

28 lbid., pp. 78-81.

La ruta del Inca Garcilaso RAQUEL CHANG-RODRÍGUEZ 
29

Entre ellos el mestizaje, como propuso Julio Ortega en un temprano trabajo, "The Discourse of Abundance», Review: Latin American Literature and Arts, 43 (1990), pp. 3-7.

30

Agradezco este señalamiento a José Antonio Mazzotti.

31

Miró Quesada, op. cit., p. 90.

Véase Historia General: 1, libro 8, cap. 12.

32

Sevillano de origen, encomendero en Cotapampa y vecino del Cuzco (CR: 1, libro 3, cap. 12, p. 153; 2, libro 7, cap. 11 , p. 114).

33

Véase Vives, Instrucción de la mujer cristiana [c.1529], Juan Justiniano (trad.), Madrid, Signo, 1936.

34

Un caso curioso de agencia femenina indígena, en este caso fallida, lo encontramos en el rechazo de la hija de Huaina Cápac a contraer matrimonio con el soldado Diego Hernández porque antes había sido sastre y de ahí su respuesta al obispo en el altar: «ĺchach munani, íchach manamunami. ... 'Quiça quiero,

Quiça no quiero'» (HG 1944

[1617]: 3, libro 6, cap. 3, p.

14). Otro episodio relacionado con el comportamiento de las mujeres españolas y las consecuencias del mucho hablar, dan lugar a una meditación sobre e matrimonio entre conquistadores y mujeres indígenas que deviene muy personal (Véase HG 1944 [1617]: 1, libro 2, cap. 1, p. 113). En un trabajo de próxima aparición me ocupo de estas y otras incidencias de género.

35

En su ensayo «Los silencios del Inca», Mundo Nuevo, 5 (1966), pp. 66-72, José Durand se percató tempranamente de su importancia.

La ruta del Inca Garcilaso RAQUEL CHANG-RODRÍGUEZ
- fueron traídos por los conquistadores - y han crecido o se han multiplicado desproporcionadamente. Considerando lo anterior, no sería desacertado proponer que los dos pueden leerse como metáforas del coloniaje: las hortalizas y las frutas representan sus efectos beneficiosos ${ }^{29}$, mientras las ratas y su secuela las trágicas consecuencias de este. En el virreinato del Perú -y en América-, por medio de la aventura imperial, ha proliferado tanto lo positivo como lo negativo del impuesto régimen; sin embargo, lo segundo, o sea, lo dañino, parece imperar.

Como señala concluyentemente el capítulo sobre las ratas, la perversidad de las plagas puede terminar con los cultivos beneficiosos. Con todo, es posible erradicar el mal: ahí está el tósigo, ahí está el victorioso enfermo en una intervención reminiscente de la lucha de don Quijote contra los molinos de viento. La narración, en efecto, propone combatir el mal, replantar las hortalizas y yerbas importadas, cosechar de nuevo: con la ayuda divina y el esfuerzo de los pobladores - es decir, los nuevos peruanos - se puede exterminar las ratas, lograr la sanación, erradicar lo nocivo del colonialismo. ¿Acaso el autor intenta establecer un contraste entre el régimen de encomiendas y el corregimiento, destacando las posibilidades del primero en tanto recompensa de los hechos de los antiguos conquistadores como su padre, y lo perjudicial del segundo, controlado por ambiciosos y corrompidos burócratas que nada hicieron para ganar la tierra y aumentar el imperio ?30. Sería difícil responder; no obstante, al enlazar ambas observaciones (sobre la reproducción de las ratas importadas y las plantas europeas sembradas en suelo andino), es evidente que el narrador valora las bondades y maldades del régimen impuesto, insta a preservar lo mejor y señala la capacidad de los pobladores - los nuevos peruanos - para, con la ayuda divina, erradicar lo dañino.

\section{Sevilla «encantadora»}

Si bien el joven Gómez Suárez de Figueroa ingresó en el continente europeo por la ciudad de Lisboa, de tantas resonancias en cuanto a la publicación de su obra, en Comentarios reales no hallamos ninguna referencia a la capital lusitana. Sevilla, la ciudad por la cual entró a España, visitó cuando residía en Montilla y a donde trasladó los restos de su padre ${ }^{31}$, figura con cierta prominencia. Si bien no ofrece una primera impresión de la villa bética, hay un pasaje donde la califica, la relaciona con la conquista del Perú y da entrada a lo femenino. La observación se enmarca dentro de la llegada del virrey Andrés Hurtado de Mendoza (1555-1560) a Paita y San Miguel de Piura, en ruta hacia Lima. Por mal comportamiento en la última villa norteña mencionada, calificado por el narrador como «exercicios poco o nada honestos», el virrey mandó apresar y retornar a España a un caballero de su séquito; también devolvió al conquistador Pedro Luis de $\mathrm{Ca}$ brera $^{32}$ y a otros casados cuyas mujeres habían permanecido en Sevilla. Si bien en el texto no hallamos otro indicio de la mala conducta de parte de Cabrera y los conquistadores reintegrados a la Península, el narrador parece excusarlos: «es verdad que la culpa más era de las mujeres que no de sus maridos, porque algunos dellos havían embiado por las suyas con mucho dinero para el camino, y, por no dexar a Sevilla, que es encantadora de las que la conocen, no quisieron obedecer a sus maridos, antes procuraron ellas con la justicia que se los embiassen a España». Las acciones de las esposas de los conquistadores tienen consecuencias costosas: «por no ir al Perú tres dellas, cuyos maridos yo conocí, perdieron los repartimientos que con la muerte de sus maridos heredavan, que valían más de cien mil ducados de renta, los cuales pudiéramos nombrar, pero es justo que guardesemes la reputación y honor de todos» (HG: 3, libro 8, cap. 4, p. 193). El breve pasaje es instructivo por varias razones. Reitera el atractivo de Sevilla, tan «encantadora» que las conquistadoras no han podido resistir su hechizo. Al mismo tiempo, el narrador enmarca el comportamiento femenino en el tradicional código matrimonial donde la castidad, la fidelidad y la obediencia son las virtudes exigidas y admiradas ${ }^{33}$. Quienes lo violen, pagarán muy caro: en este caso las desobedientes perdieron un cuantioso caudal.

No obstante, el episodio muestra a mujeres listas a subvertir la norma con el propósito de lograr su objetivo: no abandonar Sevilla y el retorno a España de los maridos ${ }^{34}$. Igualmente fascinante es el silencio que el narrador guarda para conservar la reputación de hombres y mujeres afectados por estas acciones $^{35}$. La conducta prudente de parte del narrador, implícita en su silencio, la encontramos muy tempranamente en la Relación 
de la descendencia del famoso Garci Pérez de Vargas (1596). En este tratado genealógico, el remoto ancestro español del Inca Garcilaso, rehúsa revelar el nombre de un caballero cristiano quien cobardemente abandona el real cuando se aproximan varios combatientes moros $^{36}$. Para no maldecir, para preservar la honra ajena, el silencio se convertirá en un rasgo estilístico clave en los escritos del Inca Garcilaso. Más importante aún, tal marca da cuenta de la postura ética que anima la obra del cronista cuzqueño.

Al orientar el análisis de Comentarios reales a la estructura profunda del texto siguiendo direcciones recientes y diferentes en la crítica garcilasista y, en este caso, apoyándome en parámetros de análisis pautados por Burke, particularmente en cuanto al escrutinio de la escena de las acciones y la dilucidación del porqué de estas, el sentido de las variadas observaciones del Inca Garcilaso en tanto su trayectoria transatlántica, se hace evidente. La indagación nos lleva a parafrasear el aserto de Fredric Jameson en The Political Unconscious. Narrative as a Socially Symbolic Art (1981): no hay palabra inocente. A pesar de la aparente candidez de las observaciones, en Comentarios reales, tampoco hay palabra inocente; cada una tiene su puesto y le otorga un matiz particular a los hechos contados. Como se ha visto, menciones circunstanciales del cabo de Passau llevan al narrador a afirmar, en moderna postura, la habitabilidad de la zona tórrida, la capacidad de sus habitantes y de quienes, como él, han cruzado la línea equinoccial. Por otro lado, la referencia al estado «selvático» de sus moradores exculpa a los Incas, quienes no intentaron conquistarlos. Por implicación, tal hazaña les corresponde a los nuevos señores de la tierra, los españoles. La dificultad de la empresa y el consecuente enaltecimiento de los soberanos del Tahuantinsuyo por haberla avanzado, se muestra nuevamente en Cartagena de Indias por medio de una iluminadora referencia donde nativos y grullas se conjuntan. La yunta de personas y aves, trae a colación un modo de agrupamiento pero también una conducta que rescata cualidades aprovechables en la vida comunitaria de animales y humanos, y en el proceso de catequesis de hombres y mujeres. Como antes los Incas, los europeos, más allá de las apariencias, deben reconocer estas aptitudes y valerse de ellas. El lamento del narrador y su insinuación del fracaso de la empresa imperial, va implícito en la observación de los años de contacto entre europeos e indígenas y el estado deplorable de los últimos. La centralidad de la experimentación, en contraste con el predominio del saber heredado o infuso, se observa en la descripción de los mosquitos de Lima y la prueba tan personal a la cual se sometió el joven viajero. Cuando se contrasta la perversidad de la plaga de ratas, animales tradicionalmente ligados en el Occidente a la peste y la destrucción, con las plantas importadas y su desmesurado crecimiento, el narrador, desde una óptica americana, indica que no todo lo recibido de Europa es aceptable. En el trasvase colonial arribaron lo bueno y lo malo, y ambos coexisten; pero cuando el balance se quiebra y lo segundo predomina, los nuevos y americanos pobladores - como en la lucha del enfermo o en la fumigación de las ratas - deben erradicarlo y plantar otra vez, con la esperanza de «cosechar», lo mejor de un hecho histórico que ha mezclado inexorablemente geografías y etnias. De los comentarios sobre Sevilla, resaltan el hechizo de la ciudad, la agencia femenina y la expresión de las consecuencias de la cultura dineraria suscitada por las riquezas del Perú. El recurso del silencio empleado aquí en referencia a la conducta de conquistadores y conquistadoras reitera la impronta ética de Comentarios reales. Al excavar en la estructura profunda de la obra maestra del Inca Garcilaso, las instancias estudiadas nos llevan a las múltiples y sutiles maneras de exponer las consecuencias del coloniaje en el virreinato del Perú; a la vez, dichos destellos narrativos muestran una visión moderna de los acontecimientos, imbuida de una deontología donde se evidencia un cierto pragmatismo y una gran preocupación por el futuro de América. Así, la ruta física del periplo transatlántico del Inca Garcilaso de la Vega, documentada en breves glosas y apartes casi imperceptibles, igualmente propone una aproximación al trayecto ideológico que conforma su derrotero intelectual y lo muestra como autor contradictorio y moderno, capaz de reconocer y asimilar las complejidades del coloniaje en su «tierra, ... el Perú» (F: Dedicatoria, 3).
36

Inca Garcilaso de la Vega, Relación de la descendencia de Garci Pérez de Vargas [1596], Raúl Porras Barrenechea (ed.), Lima, UNMSM, 1951, p. 35. 